\title{
BMJ Open Healthcare utilisation, cancer screening and potential barriers to accessing cancer care in rural South West Nigeria: a cross-sectional study
}

\author{
Avinash Sharma (1) , ${ }^{1}$ Olusegun Isaac Alatise, ${ }^{2}$ Kelli O'Connell, ${ }^{3}$ \\ Samson Gbenga Ogunleye, ${ }^{4}$ Adewale Abdulwasiu Aderounmu, ${ }^{4}$ \\ Marquerite L Samson, ${ }^{3}$ Funmilola Wuraola, ${ }^{2}$ Olalekan Olasehinde, ${ }^{2}$ \\ T Peter Kingham, ${ }^{1}$ Mengmeng Du ${ }^{3}$
}

To cite: Sharma A, Alatise 01 , 0 'Connell $\mathrm{K}$, et al. Healthcare utilisation, cancer screening and potential barriers to accessing cancer care in rural South West Nigeria: a crosssectional study. BMJ Open 2021;11:e040352. doi:10.1136/ bmjopen-2020-040352

- Prepublication history and additional supplemental material for this paper are available online. To view these files, please visit the journal online (http://dx.doi.org/10.1136/ bmjopen-2020-040352)

Received 12 May 2020 Accepted 12 July 2021

D Check for updates

(C) Author(s) (or their employer(s)) 2021. Re-use permitted under CC BY-NC. No commercial re-use. See rights and permissions. Published by BMJ.

For numbered affiliations see end of article.

\section{Correspondence to}

Dr Avinash Sharma;

avinash.s.sharma@gmail.com and

Dr Mengmeng Du, Epidemiology and Biostatistics, Memorial Sloan Kettering Cancer Center, New York, New York, USA; dumeng@mskcc.org

\section{ABSTRACT}

Background/aims Cancer burden is predicted to double by 2030 in sub-Saharan Africa; access to healthcare services for cancer management is a priority in the region. In Nigeria, National Cancer Control Plan aims to ensure $>50 \%$ cancer screening of eligible populations by 2022 for all Nigerians. We describe healthcare utilisation, cancer screening activities and potential barriers to accessing cancer care within an understudied rural community-based adult population in South West Nigeria.

Methods In April 2018, we conducted a cross-sectional study of community-based adults ( $>18$ years) $\sim 130$ $\mathrm{km}$ east of Ibadan, $250 \mathrm{~km}$ from Lagos in 0sun State, South West Nigeria. Participants completed a face-toface survey in local dialect. We used a questionnaire to assess demographics, health status, income, medical expenditures, doctor visits and cancer screening history. Results We enrolled 346 individuals: with median age of 52 years and $75 \%$ women. Of the entire cohort, $4 \%$ had medical insurance. $46 \%$ reported a major medical cost in the last year. Cancer screening activities were infrequent in eligible participants: $1.5 \%$ reported having had cervical cancer screening, $3.3 \%$ mammogram and $5 \%$ colonoscopy screening. Cancer screening assessment was less frequent in those with less income and lower education levels. Using a multivariable logistic regression model including personal income, insurance status and education, higher personal income was associated with more cancer screening activity $(0 \mathrm{R} 2.7,95 \% \mathrm{Cl}$ 1.3 to $5.7, p<0.01$ ). Despite this, most individuals had contact with a primary healthcare doctor $(52 \%$ in the last year), and over 70\% access to radio and TV suggesting the opportunity to expand communitybased screening interventions and awareness exists. Conclusions Despite national increases in cancer cases, we highlight a deficiency in cancer screening and universal healthcare coverage within a community-based adult Nigerian population. Subject to availability of governmental resources, increasing financial risk protection, awareness and targeted resource allocation may help expand access in Nigeria.
Strengths and limitations of this study

- Rigorously trained interviewers fluent in the local dialect collected contemporary perspectives of potential barriers to accessing medical and cancer care in a crucially understudied population in rural South West Nigeria.

- Questionnaire items derived by adapting features from validated and/or widely implemented local or nationwide surveys and tailored to the local population in collaboration with local clinicians, epidemiologists and nutritionists.

- Study conducted in conjunction with local community healthcare workers and the regional tertiary referral hospital to help build capacity, increase healthcare awareness and establish a sustained relationship with these rural communities.

- Potential for measurement error or recall bias, as we relied on individuals to retrospectively describe their own health and socioeconomic status as well as their interactions with healthcare services.

- Survey conducted at a single time (midweek, during the day) in two geographical locations, which may have affected sample composition (eg, more women than men).

\section{INTRODUCTION}

The burden of non-communicable disease (NCD), in particular cancer, in sub-Saharan Africa is well documented. ${ }^{1-3}$ According to recent International Agency for Research on Cancer Global Cancer Observatory estimates, by $2030,75 \%$ of new cancer cases will be within low-to-middle-income countries (LMICs) ${ }^{45}$ In sub-Saharan Africa, despite the fact that cancer burden is predicted to double by 2030 , the entire region accounts for $<1 \%$ of worldwide medical cancer expenditures. ${ }^{6-8}$ Central to addressing the growing burden of cancer in sub-Saharan Africa is the need 
to improve access to cancer care services for screening, prevention and treatment. $^{9}$

NCDs, including cancer, threaten to overwhelm fragile health systems in sub-Saharan Africa and lead to dramatic rises in health and social care costs in the near term. ${ }^{710} \mathrm{In}$ the region, out-of-pocket health expenditures are a major contributor to poverty, ${ }^{11-13}$ and a lack of adequate social protection has the potential to drive families and individuals further into poverty. In Nigeria, universal healthcare coverage in the form of the National Health Insurance Scheme (NHIS) was implemented in 2005, with an overarching goal of universal health coverage for all Nigerians. ${ }^{14}$ However, uptake has been limited and restricted, ${ }^{15}$ and as a result, the large majority of Nigerians still face significant financial burden when healthcare needs arise. ${ }^{1516}$

In Nigeria, cancer incidence and mortality are increasing, and women have a higher cancer incidence than men. ${ }^{17}$ The most common forms of cancer in Nigeria are breast and cervical, with these accounting for over $50 \%$ of cancer deaths. ${ }^{17-19}$ Regionally, the need to improve access to cancer services for early detection has been recognised, with a focus on these cancers. In 2018, Nigeria launched the 'National Cancer Control Plan 2018-2022', with the goal to make screening services available for all Nigerians and at least 'greater than 50\% screening of all eligible populations by $2022,{ }^{20}$ Despite this, the current state of cancer screening activities and barriers to care in this region (esp. rural areas) is not well defined or documented. This gap limits our ability to define actionable steps towards improving access and achieving the established screening goal. National programmes for screening breast and cervical cancers are lacking. Typically, screening interactions occur at primary healthcare facilities or community health clinics-often for women when they are being seen during pregnancy or for other related health issues such as immunisations. Screening services for cervical and breast cancers have been implemented sporadically by both government and non-government organisations but predominantly in urban areas. The overwhelming majority of individuals in the region are symptomatic when they present with disease. With $50 \%$ of Nigeria's population living in rural areas, ${ }^{21}$ we hypothesise that unique challenges may exist for individuals in these communities, where nationwide initiatives may have limited reach.

This study aimed to describe potential barriers to accessing cancer care within a rural community-based adult population in South West Nigeria. This study was performed as part of a broader community-based capacity building project in South West Nigeria ${ }^{22}$ investigating potentially modifiable cancer risk factors in the setting of rising rates of cancer in the region. ${ }^{6} 192023$ Herein, we report health insurance coverage and socioeconomic status in relation to health conditions, health expenditures and cancer screening assessment and provide a snapshot of the health needs and burden faced by individuals in the region.

\section{METHODS}

During April 2018, a cross-sectional study of communitybased adults was conducted in Osun State, South West Nigeria. Two rural towns Ijebu-Jesa and Ere-Jesa (approximately $130 \mathrm{~km}$ east of Ibadan, $250 \mathrm{~km}$ from Lagos and on latitude 7.45 degrees north within the rain forest belt), were selected at random. These towns were in proximity to Obafemi Awolowo University Teaching Hospitals Complex, Ile-Ife, the main tertiary referral centre in the region. This study was part of a broader capacity building project in the region to improve cancer care and prevention in this understudied population. It served as a baseline study to assess access to cancer services as well as a pilot study to explore endemic risk factors for cancersuch as unique dietary, exercise and environmental exposures.

\section{Patient and public involvement}

Prior to the study, local community leaders in the towns were contacted, and the goals of the research were explained. In the time leading up to the study, healthcare workers and community leaders notified and mobilised all potential participants in the two communities. They were also involved in the design of the study and in disseminating the results to all participants. Participants were notified of the study through discussion at the weekly local community meetings in the month leading up to the study, advertisements on local radio stations and community workers visiting regional sites.

\section{Participants}

Adults $>18$ years in the two towns were invited to participate. Adult participants were consecutively enrolled on arrival at predesignated locations (main town hall) in the two towns. Sample size for this study was therefore based on resource capacity of each town hall, available number of interviewers to administer the questionnaire and the size of each rural community in which we recruited; enrolment was capped at a maximum of 300 participants at Ijebu-Jesa and 100 at Ere-Jesa over the recruitment period. All study participants received blood pressure checks, and health promotion talks were held for those waiting to be surveyed. Study participants were given a small stipend to cover their transportation costs to the study venue on the study day (300 Naira, 80 US cents). This amount was determined by local healthcare workers.

\section{Questionnaire}

The survey consisted of a questionnaire to gather quantitative data on demographics, health status, income, medical expenditures, dietary habits, physical activity, family history, screening history, medical history, reproductive history, primary healthcare visits, medication use and environmental exposures (see online supplemental file 2). The questionnaire used was developed in collaboration with local clinicians, epidemiologists and nutritionists and was derived by adapting features from validated and/or widely implemented local or 
nationwide surveys. This included the Nigerian Demographic and Health Survey, ${ }^{24}$ Nigeria General Household Survey, ${ }^{25}$ WHO-endorsed Global Physical Activity Questionnaire $^{26}$ and Nurses' Health Study Questionnaire. ${ }^{27-30}$ We therefore did not additionally test for reliability, and our study was intended to capture a cross-sectional snapshot of our rural communities. However, we expect low social mobility in our two rural Nigerian towns and therefore limited changes over time for the sociodemographic features collected in our questionnaire.

\section{Data collection}

After obtaining informed consent, the study participants underwent a 50-60 min one-on-one, face-to-face survey conducted in the local Yoruba dialect by a trained research assistant. All research assistants underwent a 2-day training programme that involved education into the research aims, methodology and ethics as well as interview techniques through role-playing exercises, pilot testing of the questionnaire and the use of electronic tablets for recording data.

\section{Outcome measures}

Cancer screening activities in screen-eligible individuals included history of cervical examination and screening test in women $>21$ years, mammogram in women $>40$ years and colonoscopy in all individuals $>50$ years. Because cervical cancer screening intervention was self-reported, screening could be by pap smear or visual inspection with acetic acid or Lugol's iodine. This could be conducted in a primary healthcare setting. Manual breast examination by a healthcare worker was not captured, and therefore, the assessed intervention evaluated management at local secondary and tertiary healthcare facilities. All of the assessed interventions were screening activities specified as part of the Nigerian National Cancer Control Plan 2018-2022. Medical expenses were defined as any 'major medical costs' as perceived by the study participant on direct questioning. This was clarified by recording the amount spent in Naira, and the medical reason for the expenditure was also documented. Demographical and socioeconomic data collected from our study population were compared with data from the Nigerian Demographic and Health Survey and the Oxford Poverty Health Indicator $^{3132}$ to assess external validity.

\section{Statistical analysis}

Data were summarised in the form of proportions and frequency tables for categorical variables. Continuous variables were summarised using mean, median and SD. Comparisons of discrete variables were computed using Fisher's exact test and multiple logistic regression. Missing data were not possible for completed questionnaires as only complete responses to questions could be processed in order to advance the survey on the electronic tablets. All analyses were conducted using SAS software V.9.4.

\begin{tabular}{|c|c|}
\hline Variable & $\mathbf{N}(\%)$ \\
\hline Median age, years (range) & $52(18-100)$ \\
\hline \multicolumn{2}{|l|}{ Sex } \\
\hline Man & $85(24.6)$ \\
\hline Woman & $261(75.4)$ \\
\hline \multicolumn{2}{|l|}{ Marital status } \\
\hline Single & $27(7.8)$ \\
\hline Married & $213(61.6)$ \\
\hline Others (divorced/cohabiting) & $106(30.6)$ \\
\hline \multicolumn{2}{|l|}{ Tribe } \\
\hline Yoruba & $332(96.0)$ \\
\hline Ibo & $5(1.4)$ \\
\hline Others & $9(2.6)$ \\
\hline \multicolumn{2}{|l|}{ Religion } \\
\hline Christian & $326(94.2)$ \\
\hline Muslim & $19(5.5)$ \\
\hline Others & $1(0.3)$ \\
\hline \multicolumn{2}{|l|}{ Education } \\
\hline No formal education & $88(25.4)$ \\
\hline Primary & $92(26.6)$ \\
\hline Secondary & $92(26.6)$ \\
\hline Vocational/technical & 45 (13.0) \\
\hline Higher & $29(8.4)$ \\
\hline \multicolumn{2}{|l|}{ Occupation } \\
\hline Unemployed & $30(8.7)$ \\
\hline Civil servant & $30(8.7)$ \\
\hline Trader & $123(35.5)$ \\
\hline Farmer & $35(10.1)$ \\
\hline Self-employed & $80(23.1)$ \\
\hline Others & 48 (13.9) \\
\hline \multicolumn{2}{|c|}{ Number of live births (women, $n=242$ ) } \\
\hline 0 & $6(2.5)$ \\
\hline 1 & $15(6.2)$ \\
\hline 2 & $23(9.5)$ \\
\hline 3 & $28(11.6)$ \\
\hline 4 & $54(22.3)$ \\
\hline 5 or more & $116(47.9)$ \\
\hline
\end{tabular}

${ }^{*} \mathrm{n}=268$ ljebu-Jesa and $\mathrm{n}=68$ Ere-Jesa.

\section{RESULTS}

A total of 346 individuals were consecutively enrolled in the study and interviewed during the recruitment period. All individuals that were interviewed provided data for analysis. The demographical features of the group are presented in table 1 . The majority of participants were Yoruba speaking $(\mathrm{n}=332,96 \%)$ and married $(\mathrm{n}=213$, $62 \%$ ) with a median age of 52 years. Women accounted 
for $75 \%$ of the cohort $(n=261)$. Most individuals had some form of education, with 166 participants (48\%) reporting more than primary school education. In addition, 30 participants $(9 \%)$ reported being unemployed. Of female participants, $70 \%$ had $\geq 4$ live births.

Overall, 155 participants (45\%) had a personal monthly income of $<10000$ Naira ( US\$1 per day), and 134 individuals $(76 \%)$ had a family monthly income of $<50000$ Naira (US\$140 per month) (table 2A). In addition, 198 participants $(57 \%)$ lived in a family home or owned an apartment. The majority of participants (92\%) reported having access to electricity, and over $70 \%$ reported access to television $(76 \%)$ or radio $(73 \%)$.

To assess the comparability of our results to the general Nigerian population, we compared the data from our study population to that recorded in the Nigerian Demographic and Health Survey (table 2B) ${ }^{31}$ Both groups had similar degrees of education at the primary level for men and women, but overall, there were fewer uneducated men and women within our surveyed population when compared with national averages. Our surveyed group also had better access to electricity, radio and television compared with the national survey group (rural). When compared with equivalent parameters for Nigeria from the Multidimensional Poverty Index developed by the Oxford Poverty and Human Development Initiative, ${ }^{32}$ our study population had similar levels of deprivation for years of schooling (defined as $<6$ years of school) and electricity (defined as no household electricity).

Within the group surveyed, cancer screening/assessment activities were limited: 2\% (4/267) of female participants had a previous cervical smear/assessment, and 3\% $(6 / 182)$ of women $>40$ years had never had a mammogram (table 3 ). The prevalence of colonoscopy screening in those $>50$ years was $5 \%(9 / 200)$. In terms of healthcare access, 180 individuals (52\%) had seen a primary healthcare doctor in the last year and were less likely to see a traditional healer during this period. Of all participants, 110 reported being diagnosed with hypertension (32\%), but most individuals were not on daily hypertensive medication $(n=324,94 \%)$. The use of other medications for primary prevention of NCDs, such as aspirin and anticholesterol medications, was also infrequent.

Only 15 individuals out of 346 (4\%) had medical insurance (table 4). For the remaining uninsured participants, $66 \%$ reported that they were unaware that health insurance existed. A further 73 participants (22\%) stated that insurance was too difficult to access. Despite this, nearly half of those surveyed $(n=160,46 \%)$ reported a major medical cost in the last year, with the majority from unforeseen events, such as acute illness, trauma or surgery (58\%). The costs incurred ranged from 5000 to 1 500000 Naira, with a median of 10000 Naira, an amount that is more than the monthly income for $\sim 45 \%$ of individuals in this study. In addition, 52 participants (33\%) reported that their major medical costs were for chronic conditions. Overall, individuals, with incomes in the lowest brackets $(<50000$ Naira), accounted for most of

\begin{tabular}{|c|c|}
\hline Variable & $\mathbf{N}(\%)$ \\
\hline \multicolumn{2}{|c|}{ Personal income (per month, in Naira) } \\
\hline$<10000$ & $155(44.8)$ \\
\hline $10000-49999$ & $139(40.2)$ \\
\hline 50000-99999 & $26(7.5)$ \\
\hline $100000-249999$ & $16(4.6)$ \\
\hline 250000-499999 & $9(2.6)$ \\
\hline$\geq 500000$ & $1(0.3)$ \\
\hline \multicolumn{2}{|c|}{ Family income (per month, in Naira) } \\
\hline$<10000$ & $117(33.8)$ \\
\hline $10000-49999$ & $147(42.5)$ \\
\hline 50000-99999 & $38(11.0)$ \\
\hline $100000-249999$ & $28(8.1)$ \\
\hline $250000-499999$ & $11(3.2)$ \\
\hline$\geq 500000$ & $5(1.4)$ \\
\hline \multicolumn{2}{|l|}{ Type of dwelling } \\
\hline Own apartment & $131(37.9)$ \\
\hline Rent apartment & $146(42.2)$ \\
\hline Family house & $67(19.4)$ \\
\hline Others & $2(0.6)$ \\
\hline
\end{tabular}

Type of toilet

$\begin{array}{lc}\text { Water system } & 151(43.6) \\ \text { Pit latrine } & 164(47.4) \\ \text { Bush } & 23(6.6) \\ \text { Bucket } & 7(2.0) \\ \text { Others } & 1(0.3) \\ \text { Water source } & \\ \text { Pipe borne/boreholes } & 185(53.5) \\ \text { Well } & 146(42.2) \\ \text { River } & 15(4.3) \\ \text { Appliances } & \\ \text { Electricity } & 318(91.9) \\ \text { Television } & 262(75.7) \\ \text { Radio } & 251(72.5) \\ \text { Refrigerator } & 154(44.5) \\ \text { Air conditioner } & 8(2.3) \\ \text { Generating set } & 99(28.6) \\ \text { Personal computer } & 38(11.0) \\ \text { None } & 18(5.2)\end{array}$

Table 2B Comparison between study sample characteristics and 2013 Nigerian National Demographic and Health Survey (NDHS)

$\begin{array}{llll}\text { NDHS } & \text { NDHS } & \text { NDHS } & \text { Current } \\ \text { urban (\%) } & \begin{array}{l}\text { rural } \\ (\%)\end{array} & \text { total (\%) } & \begin{array}{l}\text { study (\%) } \\ \end{array}\end{array}$

\begin{tabular}{ccccc} 
Cooking fuel & & & & \\
Electricity & 0.7 & 0.2 & 0.4 & 10.7 \\
\hline
\end{tabular}

Continued 


\begin{tabular}{|c|c|c|c|c|}
\hline $\begin{array}{l}\text { Liquefied } \\
\text { petroleum } \\
\text { gas/natural } \\
\text { gas/biogas }\end{array}$ & 4.6 & 0.5 & 2.3 & 21.1 \\
\hline Kerosene & 47.6 & 8.7 & 25.5 & 31.8 \\
\hline Charcoal & 5.3 & 1.6 & 3.2 & 2.3 \\
\hline Wood & 37.9 & 83.3 & 63.7 & 34.1 \\
\hline \multicolumn{5}{|l|}{ Electricity } \\
\hline Yes & 83.6 & 34.4 & 55.6 & 91.9 \\
\hline No & 16.3 & 65.4 & 44.2 & 8.1 \\
\hline Missing & 0.1 & 0.2 & 0.2 & 0 \\
\hline \multicolumn{5}{|l|}{$\begin{array}{l}\text { Household } \\
\text { appliances }\end{array}$} \\
\hline Radio & 77.7 & 61.3 & 68.3 & 72.5 \\
\hline Television & 73.2 & 28.2 & 47.6 & 75.7 \\
\hline Refrigerator & 32.5 & 7.5 & 18.3 & 44.5 \\
\hline \multicolumn{5}{|l|}{$\begin{array}{l}\text { Means of } \\
\text { transportation }\end{array}$} \\
\hline Bicycle & 12.7 & 18.3 & 18.3 & 0.9 \\
\hline $\begin{array}{l}\text { Motorcycle/ } \\
\text { scooter }\end{array}$ & 27.0 & 31.2 & 31.2 & 15.0 \\
\hline \multirow[t]{2}{*}{ Car/truck } & 14.4 & 8.7 & 8.7 & 12.1 \\
\hline & $\begin{array}{l}\text { NDHS } \\
\text { woman } \\
(\%)\end{array}$ & $\begin{array}{l}\text { NDHS } \\
\operatorname{man}(\%)\end{array}$ & $\begin{array}{l}\text { Current } \\
\text { study } \\
\text { woman } \\
(\%)\end{array}$ & $\begin{array}{l}\text { Current } \\
\text { study man } \\
(\%)\end{array}$ \\
\hline \multicolumn{5}{|l|}{ Education } \\
\hline $\begin{array}{l}\text { No formal } \\
\text { education }\end{array}$ & 37.8 & 21.2 & 28.7 & 15.3 \\
\hline Primary & 17.3 & 16.7 & 26.8 & 25.9 \\
\hline Secondary & 35.8 & 47.7 & 28.0 & 22.4 \\
\hline $\begin{array}{l}\text { More than } \\
\text { secondary }\end{array}$ & 9.1 & 14.3 & 16.5 & 36.5 \\
\hline
\end{tabular}

those that incurred major medical costs in the last 2 years (74.4\%), had more visits to their primary care doctor in the year $(75.6 \%)$ and higher levels of hypertension $(80.4 \%)$.

Within eligible populations, we performed analysis to look for the association between cancer screening activity and income, insurance status and education (table 5). Individuals with lower levels of income were less likely to have had cancer screening assessments. Cancer screening activity was more frequent in those with higher levels of education. No significant relationship was observed by insurance status or other factors that were assessed. In a multivariable logistic regression model including personal income, insurance status and education, the only statistically significant OR for association with cancer screening activity was observed for personal income (personal income OR 2.7, 95\% CI 1.3 to 5.7, $\mathrm{p}<0.01$; education level OR 1.7, 95\% CI 0.98 to $2.7, \mathrm{p}=0.06$; and insurance status OR $4.3,95 \%$ CI 0.8 to $23.1, \mathrm{p}=0.09$ ).
Table 3 Screening activities, access to medical services and health conditions

\begin{tabular}{|c|c|}
\hline Variable & $\mathbf{N}(\%)$ \\
\hline \multicolumn{2}{|l|}{ Cancer screening } \\
\hline $\begin{array}{l}\text { Cervical cancer assessment (if woman }>21 \text {, } \\
n=261 \text { ) }\end{array}$ & $4(1.5)$ \\
\hline $\begin{array}{l}\text { Previous mammogram (if woman }>40, \\
n=183 \text { ) }\end{array}$ & $6(3.3)$ \\
\hline Previous colonoscopy (if $>50$ years, $n=190$ ) & $9(4.5)$ \\
\hline \multicolumn{2}{|l|}{ Last primary healthcare physician visit } \\
\hline$<1$ year ago & $180(52.0)$ \\
\hline $1-4$ years ago & $93(26.9)$ \\
\hline $5-10$ years ago & $32(9.2)$ \\
\hline$>10$ years ago & $41(11.8)$ \\
\hline \multicolumn{2}{|l|}{ Last time seen traditional healer } \\
\hline Never & $254(73.4)$ \\
\hline$<2$ years ago & $66(19.1)$ \\
\hline$\geq 2$ years ago & $26(7.5)$ \\
\hline Hypertension & $110(31.8)$ \\
\hline Diabetes & $16(4.6)$ \\
\hline High cholesterol & $24(6.9)$ \\
\hline Stroke & $18(5.2)$ \\
\hline \multicolumn{2}{|l|}{ Alcohol use* } \\
\hline No & $227(65.6)$ \\
\hline Yes, drank in past but quit & $65(18.8)$ \\
\hline Yes, currently drinks alcohol & $54(15.6)$ \\
\hline \multicolumn{2}{|l|}{ Smoking status $\dagger$} \\
\hline Never & $303(87.6)$ \\
\hline Ever & $43(12.4)$ \\
\hline \multicolumn{2}{|l|}{ Medication use } \\
\hline Reported ant-hypertensive use & $78(22.5)$ \\
\hline Reported aspirin use & $89(25.7)$ \\
\hline Reported anticholesterol use & $7(2.0)$ \\
\hline Reported herbal supplement use & $233(67.3)$ \\
\hline \multicolumn{2}{|l|}{ Oral contraceptive use } \\
\hline Never & $175(67.0)$ \\
\hline Past use & $64(24.5)$ \\
\hline Current use & $22(8.4)$ \\
\hline
\end{tabular}

*Participants were asked 'Have you had 10 or more drinks of alcohol in your life?'

†Participants were asked 'Have you smoked five packs of cigarettes (100) or more in your lifetime?'

\section{DISCUSSION}

We performed a cross-sectional community-based study in Osun State, Nigeria, to provide a snapshot of the challenges faced in the management of NCDs in the region. This study was conducted with an emphasis on cancer within broader research aims of identifying risk factors (lifestyle, diet and biological) associated with 


\begin{tabular}{|c|c|}
\hline Variable & $\mathbf{N}(\%)$ \\
\hline \multicolumn{2}{|l|}{ Insurance } \\
\hline No & $331(95.7)$ \\
\hline Yes & $15(4.3)$ \\
\hline \multicolumn{2}{|c|}{ Last time used insurance } \\
\hline In the last 2 years & $6(40.0)$ \\
\hline$>2$ years ago & $9(60.0)$ \\
\hline \multicolumn{2}{|c|}{ How many family members covered by insurance } \\
\hline None & $331(95.7)$ \\
\hline $1-2$ & $8(2.3)$ \\
\hline $3-4$ & $3(0.9)$ \\
\hline 5 or more & $4(1.2)$ \\
\hline
\end{tabular}

Reasons for not having insurance $(n=331)$

\begin{tabular}{|cc}
\hline Expense & $32(9.7)$ \\
\hline Lack of coverage & $13(3.9)$ \\
\hline Too difficult to access & $73(22.1)$ \\
\hline Others & $217(65.6)$ \\
\hline Major medical costs in the last 2 years \\
\hline No & $186(53.8)$ \\
\hline Yes & $160(46.2)$ \\
\hline Estimated amount & \\
\hline$<10000$ Naira & $73(45.6)$ \\
\hline 10000-49 000 Naira & $38(23.8)$ \\
\hline $50000-99$ 999 Naira & $16(10.0)$ \\
\hline$>100000$ Naira & $22(13.8)$ \\
\hline Unknown & $11(6.9)$ \\
\hline Reasons for major medical costs $(\mathrm{n}=158)$ \\
\hline Surgery & $17(10.8)$ \\
\hline Chronic conditions & $52(32.9)$ \\
\hline Acute illness/trauma & $74(46.8)$ \\
\hline Other/multiple reasons & $15(9.5)$ \\
\hline Amount spent (continuous) & $10000(50-1500000)$ \\
\hline Overall median (range) & $5000(50-400000)$ \\
\hline Median amount spent by reason (range) \\
\hline Surgery & $60000(7000-150000)$ \\
\hline Chronic conditions & $1800-500000)$ \\
\hline Other/multiple reasons & \\
\hline
\end{tabular}

the rising cancer incidence in the region. We observed that screening assessment for breast, cervical and colon cancers (the major contributors to cancer morbidity in the region) ${ }^{61933}$ were extremely low. This observation was despite a median age of 52 years and a high representation of women. In addition, $<5 \%$ of the surveyed population possessed universal healthcare in the form of health insurance. We also found low incomes, high fertility rates and evidence of poorly controlled chronic diseases, such as
Table 5 Association between cancer screening activity and income, insurance and education $(n=310)^{*}$

\begin{tabular}{|c|c|c|c|}
\hline Variable & $\begin{array}{l}\text { Cancer } \\
\text { screening } \\
(n=17)\end{array}$ & $\begin{array}{l}\text { No cancer } \\
\text { screening } \\
(n=293)\end{array}$ & $\begin{array}{l}\mathbf{P} \\
\text { valuet }\end{array}$ \\
\hline \multicolumn{4}{|c|}{ Personal income (per month, in Naira) } \\
\hline$<10000$ & 2/138 (1.5) & 140/138 (98.5) & \\
\hline $10000-49999$ & $9 / 122(7.4)$ & 115/122 (92.6) & $<0.01$ \\
\hline$>50000$ & $6 / 43(14.0)$ & $38 / 43(86.0)$ & \\
\hline \multicolumn{4}{|c|}{ Family income (per month, in Naira) } \\
\hline$<10000$ & $1 / 108(0.9)$ & 107/108 (99.1) & \\
\hline $10000-49999$ & $8 / 129(6.2)$ & $121 / 129$ (93.8) & $<0.01$ \\
\hline$>50000$ & $8 / 66(12.1)$ & $58 / 66(87.9)$ & \\
\hline \multicolumn{4}{|l|}{ Insurance status } \\
\hline No & $15 / 290(5.2)$ & $275 / 290(94.8)$ & 0.12 \\
\hline Yes & 2/13 (15.4) & $11 / 13(84.6)$ & \\
\hline \multicolumn{4}{|l|}{ Education } \\
\hline $\begin{array}{l}\text { No formal } \\
\text { education }\end{array}$ & $1 / 86(1.2)$ & 85/86 (98.8) & 0.04 \\
\hline Primary & $3 / 83(3.6)$ & 80/83 (96.4) & \\
\hline Secondary & 8/78 (10.3) & 70/78 (89.7) & \\
\hline Higher & $5 / 56(8.9)$ & $51 / 56(91.1)$ & \\
\hline
\end{tabular}

No association by gender, marital status and religion.

*Adjusted for eligible population, whereby cancer screening activities defined as history of cervical assessment in women $>21$ years, mammogram in women $>40$ years and colonoscopy in all individuals $>50$ years.

†Fisher's exact test for association.

hypertension, in our cohort. The rates are comparable to national averages (suggesting our sample sits between the urban/rural divide $)^{31}$ and likely represent broad health and development deficiencies present in the community. For example, the high prevalence of hypertension in this population is remarkably similar to that reported in a systematic review and meta-analysis conducted in the region. ${ }^{34}{ }^{35}$ The high burden of hypertension in the region has also been recently acknowledged by the WHO in its efforts to control hypertension in Nigeria. ${ }^{36}$

Previous studies conducted in the region ${ }^{37-45}$ have demonstrated that poor access to cancer services is associated with late presentation and high incidence/mortality ratio. ${ }^{546}$ This highlights a need to develop sound healthcare infrastructure, whereby individuals can be screened for asymptomatic disease and also adequately access services in a timely fashion when symptomatic. Our study identifies that screening activities may be lacking through either delivery or uptake and that the potential cost implications of accessing treatment when symptoms arise, in the absence of adequate health insurance, can be high. The experience from other sub-Saharan African nations suggests that individuals seeking cancer services face significant barriers to access. ${ }^{38} 3947-50$ The Nigerian 'National Cancer Control Plan 2018-2022' 
specifically details goals to make screening services and early detection of cancer available for all Nigerians and to improve access to quality, cost-effective and equitable diagnostic and treatment services for cancer care. This is centred around investment in eight public comprehensive cancer centres covering all geopolitical zones, as well as the implementation of various screening strategies throughout different sectors of the health system. ${ }^{20}$ Our results suggest that considerable work is required to reach the goal of "greater than $50 \%$ screening of "eligible populations" by 2022 '. ${ }^{20}$ We assessed cancer screening using measures that are recommended in this national plan. The methods we assessed are accessed at different levels of the healthcare system-cervical cancer assessment predominantly at a primary healthcare level, breast cancer at secondary/tertiary level through mammography and colon cancer at tertiary level through colonoscopy. While our analysis provides some idea of how individuals may have navigated the health system, further detailed study is required to look at specific engagement at these different levels to inform appropriate resource allocation.

It is important to acknowledge that cancer screening in LMICs requires measures tailored to local capacity and disease prevalence. For breast cancer, although mammography remains the gold standard for early detection of breast cancer, the Breast Health Global Initiative resource-stratified guidelines recommend clinical breast examination as a practical and necessary alternative for early detection in low-resource settings. ${ }^{19} 4851$ This has been recommended in local policy and was not assessed in the current study. ${ }^{20}$ Despite this, with over $50 \%$ of individuals in this study visiting a primary healthcare doctor in the last year, our findings strongly support the need to concentrate cancer screening efforts at primary healthcare where possible through the use of similar interventions. Colon cancer screening by colonoscopy for those over the age of fifty as recommended in highincome countries does not exist in sufficient capacity for this to be recommended in an LMIC setting. ${ }^{52}$ Efforts to intervene at primary healthcare level through the use of stool testing and symptom stratification are ongoing. ${ }^{53} 54$ Overall, education, training and adequately resourcing community healthcare workers and physicians at primary healthcare level for cancer screening assessment are essential.

We demonstrated that both income and medical expenditure relative to this level of income, compounded by the lack of universal healthcare coverage, must be factored into strategies laid out to address cancer control. The costs of the screening interventions assessed in this study relative to income are prohibitive for the majority of individuals without government subsidy: approx. US $\$ 50$, $\sim 18000$ Naira (for mammography); US $\$ 15, \sim 3000$ Naira (cervical smear). This is compounded by the finding of only $4 \%$ of our cohort having health insurance coverage. In addition, major medical costs were incurred by over half of those interviewed, and a significant proportion of these costs were for chronic diseases (33\%). Those individuals with the lowest income were more likely to report visits to the doctor, chronic disease and significant 'out-of-pocket' medical expenditures. The Nigerian NHIS has been in place since 2005. When it was introduced, state governments were instructed to adopt the programme for their employees in the formal sector. After insuring government employees, state governments were instructed to expand coverage across all individuals with the goal of universal health coverage. ${ }^{1415}$ Recent reports confirm that this expansion has been limited in Nigeria. In line with previous studies, our data indicate that the NHIS is severely underused in the community population. ${ }^{15} 16$ The state health insurance scheme has been instituted in only two out of 36 states of the federation at community level, and this has not been the case in Osun State where the study took place. ${ }^{15}$

We found wide range of 'major' medical expenditure in our study group, with a median expenditure exceeding the monthly salary of $\sim 45 \%$ of the group. It is important to note that we did not obtain information on total household expenditures to allow a relative assessment of the amount spent on medical costs and, in turn, determine 'catastrophic' costs. ${ }^{16}$ However, based on income and demographical comparisons with other groups studied in the region, it is likely that catastrophic spending is high. ${ }^{55}$ Further research into how the money to cover medical expenditure is generated (ie, personal savings, family savings and loans) is required. Taken together with prior work in the region, ${ }^{56}{ }^{57}$ it is evident that risk pooling and financial risk protection are required for the provision of preventative and therapeutic NCD health services.

While we did not directly assess awareness of cancer screening, we did demonstrate an association between cancer screening activity and education level. Levels of education have been associated with awareness and accessing cancer services in previous studies. ${ }^{38} 454758$ In addition to this, we also found that $\sim 75 \%$ of participants had access to radio and/or television within family and social networks, suggesting that mass communication channels to promote health awareness exist. In fact, these facilitated the current study when combined with strategies using mobile phone technologies. More broadly, these channels represent promising avenues to promote health and prevention of disease in the region. ${ }^{59}$ In addition, 'demand-side' approaches to resource allocation, such as the stipend we provided for travel in the study or e-vouchers, ${ }^{6061}$ are likely to be well received by the community and may promote uptake of health screening activities.

A strength of this study is that it was performed within the community and involved trained research staff fluent in the local dialect and used a validated questionnaire. The study was performed in conjunction with local community healthcare workers and the tertiary referral hospital, which was intended to help residents develop an awareness of how and where healthcare can be accessed in the area and to establish a sustained relationship with this community. Limitations of this work include the 
potential for misclassification and recall bias, as we relied on individuals to retrospectively describe their own health and socioeconomic status as well as their interactions with healthcare services. While we have documented low levels of screening activities and associations with income and education, we did not directly require individuals to state specifically their personal reasons for not being screened; we were therefore unable to delineate specific barriers to cancer screening, such as emotional barriers (eg, concern about cancer diagnosis and limited awareness) and barriers to access (eg, screening locations, availability of transportation and limited finances). Detailed qualitative analysis of these barriers would be worthwhile and is the subject of our future work in the region. In addition, while the study sample was chosen at random and consecutive individuals were enrolled, the survey was conducted at a single time that was midweek, during the day; this timing may have affected our sample composition. For instance, $75 \%$ of participants in our study were women, which may potentially limit the generalisability of our findings. However, it is reassuring we observed overall consistency with national demographical indicators (eg, income, education and living conditions), which indicates that our sample is likely reflective of rural community-dwelling individuals in the wider region. ${ }^{31} 32$

In summary, our results highlight infrequent cancer screening activities in a Nigerian community population and identify areas that can be targeted to address this, including the use of measures focused at primary healthcare level, financial risk protection, awareness and strategic resource allocation.

\section{Author affiliations}

${ }^{1}$ Surgery, Memorial Sloan Kettering Cancer Center, New York, New York, USA

${ }^{2}$ Surgery, Obafemi Awolowo University Teaching Hospitals Complex, Ile-Ife, Osun

State, Nigeria

${ }^{3}$ Epidemiology and Biostatistics, Memorial Sloan Kettering Cancer Center, New York, New York, USA

${ }^{4}$ Surgery, Obafemi Awolowo University Teaching Hospital Complex, Ile-lfe, Osun State, Nigeria

Acknowledgements The authors would like to acknowledge the dedicated research team at OAUTHC for their efforts in this project, the local community leaders and healthcare workers and the support from Prof Adesegun Fatusi and his research staff.

Contributors AS: initial conception, study and questionnaire design, data collection, data analysis and manuscript writing. OIA: initial conception, study and questionnaire design and manuscript revision. K0: data and statistical analysis, questionnaire design and manuscript revision. OSG and AAA: study organisation, data collection and manuscript revision. MLS and FW: study and questionnaire design and manuscript revision. 00: study design, data collection and manuscript revision. TPK: initial conception, study design, overall supervision and manuscript revision. MMD: initial conception, study and questionnaire design, overall supervision and manuscript revision.

Funding This research was conducted with the support of the African Research Group for Oncology (ARGO) consortium. The consortium was initiated using a pilot grant funding from the National Cancer Institute's (NCl) Center for Global Health to perform dedicated cancer research in the region. This research was supported by the National Cancer Institute grant numbers R01 CA246620 and P30 CA008748.

Competing interests None declared.

Patient consent for publication Not required.
Ethics approval The study was approved by the Obafemi Awolowo University institutional ethics review committee.

Provenance and peer review Not commissioned; externally peer reviewed.

Data availability statement № additional data available.

Supplemental material This content has been supplied by the author(s). It has not been vetted by BMJ Publishing Group Limited (BMJ) and may not have been peer-reviewed. Any opinions or recommendations discussed are solely those of the author(s) and are not endorsed by BMJ. BMJ disclaims all liability and responsibility arising from any reliance placed on the content. Where the content includes any translated material, BMJ does not warrant the accuracy and reliability of the translations (including but not limited to local regulations, clinical guidelines, terminology, drug names and drug dosages), and is not responsible for any error and/or omissions arising from translation and adaptation or otherwise.

Open access This is an open access article distributed in accordance with the Creative Commons Attribution Non Commercial (CC BY-NC 4.0) license, which permits others to distribute, remix, adapt, build upon this work non-commercially, and license their derivative works on different terms, provided the original work is properly cited, appropriate credit is given, any changes made indicated, and the use is non-commercial. See: http://creativecommons.org/licenses/by-nc/4.0/.

ORCID iD

Avinash Sharma http://orcid.org/0000-0003-3501-5432

\section{REFERENCES}

1 Niessen LW, Mohan D, Akuoku JK, et al. Tackling socioeconomic inequalities and non-communicable diseases in low-income and middle-income countries under the sustainable development agenda. Lancet 2018;391:2036-46.

2 Ezzati M, Pearson-Stuttard J, Bennett JE, et al. Acting on noncommunicable diseases in low- and middle-income tropical countries. Nature 2018;559:507-16.

3 NCD Countdown 2030 collaborators. NCD countdown 2030: worldwide trends in non-communicable disease mortality and progress towards sustainable development goal target 3.4. Lancet 2018;392:1072-88

4 The Lancet. GLOBOCAN 2018: counting the toll of cancer. Lancet 2018;392:985.

5 Bray F, Ferlay J, Soerjomataram I, et al. Global cancer statistics 2018: GLOBOCAN estimates of incidence and mortality worldwide for 36 cancers in 185 countries. CA Cancer J Clin 2018;68:394-424.

6 Olaleye O, Ekrikpo U. Epidemiology of cancers in Sub-Saharan Africa. In: Adedeji OA, ed. Cancer in Sub-Saharan Africa: current practice and future. Cham: Springer International Publishing, 2017: 3-19.

7 Mostert S, Njuguna F, Olbara G, et al. Corruption in health-care systems and its effect on cancer care in Africa. Lancet Oncol 2015;16:e394-404.

8 Harford JB. Barriers to overcome for effective cancer control in Africa. Lancet Oncol 2015;16:e385-93.

9 UN General Assembly. Transforming our world: the 2030 agenda for sustainable development, 2015. Available: https://www.undp. org/content/undp/en/home/sustainable-development-goals.html [Accessed 23 Aug 2019].

10 Douthit NT, Alemu HK. Social determinants of health: poverty, national infrastructure and investment. BMJ Case Rep 2016;2016:bcr2016215670

11 Attia-Konan AR, Oga ASS, Touré A, et al. Distribution of out of pocket health expenditures in a sub-Saharan Africa country: evidence from the national survey of household standard of living, Côte d'Ivoire. BMC Res Notes 2019;12:25.

12 Leive A, Xu K. Coping with out-of-pocket health payments: empirical evidence from 15 African countries. Bull World Health Organ 2008;86:849-56.

13 Xu K, Evans DB, Kawabata K, et al. Household catastrophic health expenditure: a multicountry analysis. Lancet 2003;362:111-7.

14 Onoka CA, Onwujekwe OE, Uzochukwu BS, et al. Promoting universal financial protection: constraints and enabling factors in scaling-up coverage with social health insurance in Nigeria. Health Res Policy Syst 2013;11:20.

15 Uzochukwu BSC, Ughasoro MD, Etiaba E, et al. Health care financing in Nigeria: implications for achieving universal health coverage. Niger J Clin Pract 2015;18:437-44.

16 Aregbeshola BS, Khan SM. Out-of-pocket payments, catastrophic health expenditure and poverty among households in Nigeria 2010. Int J Health Policy Manag 2018;7:798-806. 
17 Jedy-Agba E, Curado MP, Ogunbiyi O, et al. Cancer incidence in Nigeria: a report from population-based cancer registries. Cancer Epidemiol 2012;36:e271-8.

18 Awodele O, Adeyomoye AA, Awodele DF, et al. Cancer distribution pattern in south-western Nigeria. Tanzan $J$ Health Res 2011;13:125-31.

19 Ishola F, Omole O. A vision for improved cancer screening in Nigeria. Lancet Glob Health 2016;4:e359-60.

20 Abuja: Federal Ministry of Health, Nigeria. Nigeria National cancer control plan 2018 - 2022, 2018.

21 The World Bank Group. World Bank staff estimates based on the United Nations Population Division's World Urbanization Prospects, 2018. Available: https://data.worldbank.org/indicator/SP.RUR.TOTL. ZS [Accessed Nov 2019].

22 Kingham TP, Alatise OI. Establishing translational and clinical cancer research collaborations between high- and low-income countries. Ann Surg Oncol 2015;22:741-6.

23 Irabor DO. Emergence of colorectal cancer in West Africa: accepting the inevitable. Niger Med J 2017;58:87-91.

24 National Population Commission (NPC) [Nigeria] and ICF International. Nigeria demographic and health survey 2013. Abuja, Nigeria, and Rockville, Maryland. USA: NPC and ICF International, 2014. https://dhsprogram.com/pubs/pdf/fr293/fr293.pdf

25 National Bureau of Statistics (NBS) - Federal Government of Nigeria. Nigeria - General Household Survey, Panel 2015-2016, Wave 3. Available: http://microdata.worldbank.org/index.php/catalog/2734/ study-description [Accessed 15 Feb 2018].

26 Cleland CL, Hunter RF, Kee F, et al. Validity of the global physical activity questionnaire (GPAQ) in assessing levels and change in moderate-vigorous physical activity and sedentary behaviour. BMC Public Health 2014;14:1255.

27 Colditz GA, Manson JE, Hankinson SE. The nurses' health study: 20 -year contribution to the understanding of health among women. $J$ Womens Health 1997;6:49-62.

28 Hu FB, Satija A, Rimm EB, et al. Diet assessment methods in the nurses' health studies and contribution to evidence-based nutritional policies and guidelines. Am J Public Health 2016;106:1567-72.

29 Willett WC, Sampson L, Stampfer MJ, et al. Reproducibility and validity of a semiquantitative food frequency questionnaire. Am J Epidemiol 1985;122:51-65.

30 Wolf AM, Hunter DJ, Colditz GA, et al. Reproducibility and validity of a self-administered physical activity questionnaire. Int J Epidemiol 1994;23:991-9.

31 Nigeria Demographic and Health Survey. Abuja, Nigeria: national population Commission. Federal Republic of Nigeria, 2014.

32 University of Oxford. "Nigeria country briefing", multidimensional poverty index data bank: Oxford poverty and human development initiative, 2017. Available: www.ophi.org.uk/multidimensionalpoverty-index/mpi-country-briefings/ [Accessed Aug 2019].

33 Morhason-Bello IO, Odedina F, Rebbeck TR, et al. Challenges and opportunities in cancer control in Africa: a perspective from the African organisation for research and training in cancer. Lancet Oncol 2013;14:e142-51.

34 Adeloye D, Basquill C, Aderemi AV, et al. An estimate of the prevalence of hypertension in Nigeria: a systematic review and metaanalysis. J Hypertens 2015;33:230-42.

35 Idris IO, Oguntade AS, Mensah EA, et al. Prevalence of noncommunicable diseases and its risk factors among ljegun-Isheri Osun residents in Lagos State, Nigeria: a community based crosssectional study. BMC Public Health 2020;20:1258.

36 World Health Organisation. Nigeria collaborates with who to curb hypertension, introduces control initiative Abeokuta, Nigeria, 2020. Available: https://www.afro.who.int/news/nigeria-collaborateswho-curb-hypertension-introduces-control-initiative\#: :text=The $\%$ 20review\%20estimated\%20that\%20prevalence,29.5\%25\%2C\% 20women\%2031.1\%25)

37 Olasehinde O, Alatise OI, Arowolo OA, et al. Barriers to mammography screening in Nigeria: a survey of two communities with different access to screening facilities. Eur J Cancer Care 2019;28:e12986.

38 McKenzie F, Zietsman A, Galukande M, et al. Breast cancer awareness in the Sub-Saharan African ABC-DO cohort: African breast cancer-disparities in outcomes study. Cancer Causes Control 2018;29:721-30.

39 Makau-Barasa LK, Greene SB, Othieno-Abinya NA, et al. Improving access to cancer testing and treatment in Kenya. J Glob Oncol 2018;4:1-8.
40 Ugwumba FO, Ekwueme OEC, Okoh AD. Testicular cancer and testicular self-examination; knowledge, attitudes and practice in final year medical students in Nigeria. Asian Pac J Cancer Prev 2016;17:4999-5003.

41 Mbamara SU, Ikpeze OC, Okonkwo JEN, et al. Knowledge, attitude and practice of cervical cancer screening among women attending gynecology clinics in a tertiary level medical care center in southeastern Nigeria. J Reprod Med 2011;56:491-6.

42 Wright KO, Kuyinu YA, Faduyile FA. Community education on cervical cancer amongst market women in an urban area of Lagos, Nigeria. Asian Pac J Cancer Prev 2010;11:137-40.

43 Aniebue PN, Aniebue UU. Awareness and practice of cervical cancer screening among female undergraduate students in a Nigerian university. J Cancer Educ 2010;25:106-8.

44 Ajape AA, Babata A, Abiola OO. Knowledge of prostate cancer screening among native African urban population in Nigeria. Nig Q J Hosp Med 2010;20:94-6.

45 Obiechina NJA, Mbamara SU. Knowledge attitude and practice of cervical cancer screening among sexually active women in Onitsha, Southeast Nigeria. Niger J Med 2009;18:384-7.

46 Kontis V, Mathers CD, Bonita R, et al. Regional contributions of six preventable risk factors to achieving the $25 \times 25$ non-communicable disease mortality reduction target: a modelling study. Lancet Glob Health 2015;3:e746-57.

47 Tiruneh FN, Chuang K-Y, Ntenda PAM, et al. Individual-level and community-level determinants of cervical cancer screening among Kenyan women: a multilevel analysis of a nationwide survey. BMC Womens Health 2017;17:109.

48 Masalu N, Serra P, Amadori D, et al. Setting up a community-based cervical screening service in a low-income country: a pilot study from north-western Tanzania. Int J Public Health 2017;62:755-62.

49 Kangmennaang J, Mkandawire P, Luginaah I. Breast cancer screening among women in Namibia: explaining the effect of health insurance coverage and access to information on screening behaviours. Glob Health Promot 2019;26:50-61.

50 Stulac S, Binagwaho A, Tapela NM, et al. Capacity building for oncology programmes in Sub-Saharan Africa: the Rwanda experience. Lancet Oncol 2015;16:e405-13.

51 Anderson BO, Yip C-H, Smith RA, et al. Guideline implementation for breast healthcare in low-income and middle-income countries: overview of the breast health global initiative global summit 2007. Cancer 2008;113:2221-43.

52 Knapp GC, Alatise OI, Olasehinde OO, et al. Is colorectal cancer screening appropriate in Nigeria? J Glob Oncol 2019;5:1-10.

53 Alatise OI, Ayandipo OO, Adeyeye A, et al. A symptom-based model to predict colorectal cancer in low-resource countries: results from a prospective study of patients at high risk for colorectal cancer. Cancer 2018;124:2766-73.

54 Knapp GC, Sharma A, Olopade B, et al. An exploratory analysis of fecal immunochemical test performance for colorectal cancer screening in Nigeria. World J Surg 2019;43:2674-80.

55 Olugbenga-Bello Al, Adebimpe WO. Knowledge and attitude of civil servants in Osun state, Southwestern Nigeria towards the national health insurance. Niger J Clin Pract 2010;13:421-6.

56 Dieleman JL, Sadat N, Chang AY, et al. Trends in future health financing and coverage: future health spending and universal health coverage in 188 countries, 2016-40. Lancet 2018;391:1783-98.

57 Dieleman J, Campbell M, Chapin A, et al. Evolution and patterns of global health financing 1995-2014: development assistance for health, and government, prepaid private, and out-of-pocket health spending in 184 countries. Lancet 2017;389:1981-2004.

58 Alatise OI, Fischer SE, Ayandipo OO, et al. Health-seeking behavior and barriers to care in patients with rectal bleeding in Nigeria. J Glob Oncol 2017;3:749-56.

59 Yang Q, Van Stee SK. The comparative effectiveness of mobile phone interventions in improving health outcomes: meta-analytic review. JMIR Mhealth Uhealth 2019;7:e11244.

60 Erwin E, Aronson KJ, Day A, et al. SMS behaviour change communication and eVoucher interventions to increase uptake of cervical cancer screening in the Kilimanjaro and Arusha regions of Tanzania: a randomised, double-blind, controlled trial of effectiveness. BMJ Innov 2019;5:bmjinnov-2018-000276:28-34.

61 Hurst TE, Semrau K, Patna M, et al. Demand-side interventions for maternal care: evidence of more use, not better outcomes. BMC Pregnancy Childbirth 2015;15:297. 